\title{
Ghrelin Enhances Olfactory Sensitivity and Exploratory Sniffing in Rodents and Humans
}

\author{
Jenny Tong, ${ }^{1}$ Erica Mannea, ${ }^{3}$ Pascaline Aimé, ${ }^{5}$ Paul T. Pfluger, ${ }^{1}$ Chun-Xia Yi, ${ }^{1}$ Tamara R. Castaneda, ${ }^{6}$ Harold W. Davis, \\ Xueying Ren, ${ }^{7,8}$ Sarah Pixley, ${ }^{2}$ Stephen Benoit, ${ }^{4}$ Karyne Julliard, ${ }^{5}$ Stephen C. Woods, ${ }^{4}$ Tamas L. Horvath, ${ }^{9}$ \\ Mark M. Sleeman, ${ }^{10}$ David D'Alessio, ${ }^{1}$ Silvana Obici, ${ }^{1}$ Robert Frank, ${ }^{3}$ and Matthias H. Tschöp ${ }^{1}$ \\ ${ }^{1}$ Division of Endocrinology, Diabetes, and Metabolism, Department of Internal Medicine, and ${ }^{2}$ Department of Cancer and Cell Biology, University of \\ Cincinnati, Cincinnati, Ohio 45267, ${ }^{3}$ Department of Psychology, University of Cincinnati, Cincinnati, Ohio 45221, ${ }^{4}$ Department of Psychiatry, University of \\ Cincinnati, Cincinnati, Ohio 45219, ${ }^{5}$ UMR5020 Neurosciences Sensorielles Comportement Cognition, Centre National de la Recherche Scientifique and \\ Universite Claude Bernard Lyon 1, 69366 Lyon, France, ${ }^{6}$ Department of Medicine, University of Toledo, Toledo, Ohio 43614, ${ }^{7}$ John B. Pierce Laboratory, \\ New Haven, Connecticut 06519, ${ }^{8}$ Department of Psychiatry, Yale University, New Haven, Connecticut 06511, ${ }^{9}$ Department of Comparative Medicine, Yale \\ University, New Haven, Connecticut 06519, and ${ }^{10}$ Regeneron Pharmaceuticals Inc., Tarrytown, New York 10591
}

Olfaction is an integral part of feeding providing predictive cues that anticipate ingestion. Although olfactory function is modulated by factors such as prolonged fasting, the underlying neural mechanisms remain poorly understood. We recently identified ghrelin receptors in olfactory circuits in the brain. We therefore investigated the role of the appetite-stimulating hormone ghrelin in olfactory processing in rodents and humans, testing the hypothesis that ghrelin lowers olfactory detection thresholds and enhances exploratory sniffing, both being related to food seeking. In rats, intracerebroventricular ghrelin decreased odor detection thresholds and increased sniffing frequency. In humans, systemic ghrelin infusions significantly enhanced sniff magnitudes in response to both food and nonfood odorants and air in comparison to control saline infusions but did not affect the pleasantness ratings of odors. This is consistent with a specific effect on odor detection and not the hedonic value of odors. Collectively, our findings indicate that ghrelin stimulates exploratory sniffing and increases olfactory sensitivity, presumably enhancing the ability to locate, identify, and select foods. This novel role is consistent with ghrelin's overall function as a signal amplifier at the molecular interface between environmental and nutritional cues and neuroendocrine circuits controlling energy homeostasis.

\section{Introduction}

Many animals rely on olfactory cues to generate behavioral responses to relevant stimuli. In particular, olfaction modulates ingestion by localizing, and discriminating among, food sources. Given the relationship between olfactory processing and food intake, changes in nutritional state would be expected to modify reactions to odors. Consistent with this, olfactory sensitivity is enhanced by fasting and reduced by feeding in rodents and humans (Goetzl and Stone, 1947; Aimé et al., 2007), and pleasantness ratings for food odors are significantly and specifically reduced in satiated humans (Havermans et al., 2009), an effect that is manifest in the orbitofrontal cortex (O'Doherty et al., 2000).

Sniffing, the first stage in olfactory processing, influences olfactory perception (Mainland and Sobel, 2006), odorant intensity

\footnotetext{
Received 0ct. 27, 2010; revised Jan. 10, 2011; accepted Feb. 22, 2011.

This work was supported by National Institutes of Health Grants 5K23DK80081 (J.T.) and R01DK069987 (M.H.T.) and the Netherlands Organization for Scientific Research-Rubicon grant (C.X.Y.). We gratefully thank Ivan de Araujo for manuscript editing and Jon Davis and James Chambers for providing technical and scientific expertise with the $\mathrm{COA}$ test. We also thank Tracy Hopkins and Jason Lee for their technical assistance and Givaudan for providing the odorants for SMT.

Correspondence should be addressed to Dr. Jenny Tong, 3125 Eden Avenue, ML 0547, Cincinnati, OH 45267. E-mail: jenny.tong@uc.edu.

DOI:10.1523/JNEUROSCI.5680-10.2011

Copyright $\odot 2011$ the authors $\quad 0270-6474 / 11 / 315841-06 \$ 15.00 / 0$
}

(Laing, 1983; Sobel et al., 2000), and odor discrimination (Mozell and Jagodowicz, 1973; Mainland and Sobel, 2006). These psychophysical findings are consistent with the observation that sniffing, even in the absence of detectable odorants, induces activity in the olfactory bulb (Hughes et al., 1969) and piriform cortex (Sobel et al., 1998), and increasing sniffing frequency is thought to be important in states of nutritional scarcity, when identification of food is critical (Kepecs et al., 2007). We therefore reasoned that manipulating hunger might influence brain circuits controlling sniffing and olfaction.

Ghrelin is an appetite-stimulating hormone produced primarily by the stomach (Kojima et al., 1999). Circulating ghrelin increases before meals and decreases during eating (Cummings et al., 2001; Tschöp et al., 2001) and has been implicated in meal initiation and short- and long-term energy regulation (Cummings, 2006). In rodents, ghrelin administration increases food intake and promotes fat accumulation (Tschöp et al., 2000). In humans, ghrelin potently induces hunger, stimulates food intake, and enhances the pleasantness of meals (Druce et al., 2005). Ghrelin also enhances the hedonic and incentive responses to food-related cues (Malik et al., 2008). Interestingly, the growth hormone secretagogue receptor (GHSR-1a), identified as the only ghrelin receptor, is expressed in the facial motor nucleus (Zigman et al., 2006), which is responsible for controlling facial structures that are involved in sniffing movements. We therefore 
tested the hypothesis that ghrelin mediates the physiological influence of fasting on sniffing and olfactory processing in rats and humans by increasing olfactory sensitivity and enhancing sniffing by acting on GHSR in central olfactory processing regions.

\section{Materials and Methods}

Animals. Male rats (300-350 g Long-Evans, Charles River and 280-350 g Wistar, Harlan) were individually housed under standard laboratory conditions, with tap water and rat chow available ad libitum, on a $12 \mathrm{~h}$ light/dark cycle. GHSR null mice $\left(\mathrm{Ghsr}^{-/-}\right)$, originally obtained from Regeneron Pharmaceuticals, have been previously described (LeSauter et al., 2009). All procedures were conducted under National Institutes of Health guidelines for the use of animals in research and approved by the University of Cincinnati Institutional Animal Care and Use Committee.

Rats were anesthetized [ketamine $(50-80 \mathrm{mg} / \mathrm{kg}$, i.p.)-xylazine $(9-13$ $\mathrm{mg} / \mathrm{kg}$, i.p.)] and equipped with an intracerebroventricular cannula positioned in the third-cerebral ventricle as previously described (Nogueiras et al., 2007). Cannula placement was assessed by injecting angiotensin II as described previously (Kampe et al., 2006). Osmotic minipumps (Alzet Osmotic Pumps; Durect) delivering ghrelin (Bachem) or vehicle (isotonic saline) were implanted subcutaneously and connected to the intracerebroventricular cannulas via a polyethylene catheter. Beginning immediately after surgery, ghrelin was infused $(2.5 \mathrm{nmol} / \mathrm{d})$ for $8 \mathrm{~d}$, a regimen that increases food intake and body weight (Theander-Carrillo et al., 2006).

Biotinylated ghrelin binding. To assess the ability of ghrelin to bind to cells in the main olfactory bulb, $100 \mu \mathrm{m}$ sections were processed for binding as described previously (Cowley et al., 2003). Briefly, saline-perfused rat brains were removed, sectioned, and immediately reacted with biotinylated ghrelin ( $1 \mu \mathrm{m}$; Phoenix Pharmaceuticals) alone or in combination with an equal amount of unlabeled (cold) ghrelin ( $1 \mu \mathrm{M}$; Phoenix Pharmaceuticals) for 20 min at $4^{\circ} \mathrm{C}$.

Expression of LacZ gene. GHSR knock-out (ko) mice were generated by replacing the coding region of the Ghsr gene with an expression cassette encoding the reporter gene LacZ. The expression of $\beta$-galactosidase ( $\beta$-gal), the product of the LacZ gene, was visualized by X-gal histochemistry (Wortley et al., 2004) or immunofluorescence (Yi et al., 2006).

Sniffing parameters in rats. Sniff frequency was detected using a video-based, fully automated behavior analysis system (HomeCageScan, Clever Sys) that recognizes, records, and quantifies the movement of the nose tip while the animal was either fully or partially reared in a home-cage environment (Steele et al., 2007). Intracerebroventricular cannulas were implanted at least $7 \mathrm{~d}$ before behavioral screening. Saline $(5 \mu$ l, i.c.v. $)(n=3)$ was injected on day 1 and ghrelin $(1 \mu \mathrm{g} / \mu \mathrm{l}$ saline $)(n=3)$ was injected on day 2. Sniffing behaviors were monitored in ad libitum-fed (Long-Evans) rats for $24 \mathrm{~h}$ after ghrelin injection.

Conditioned odor aversion. Rats $(n=19$, Wistar) were habituated for 1 week to a $20 \mathrm{~h} / \mathrm{d}$ water and food restriction schedule, with food and water limited to 1:00-5:00 P.M. (dark cycle). Animals were tested daily during the fasting (10:00 A.M.) and satiated (6:00 P.M.) states, the zenith and nadir, respectively, of endogenous ghrelin levels (Cummings et al., 2001). The conditioned olfactory aversion (COA) paradigm and assessment of licking be-

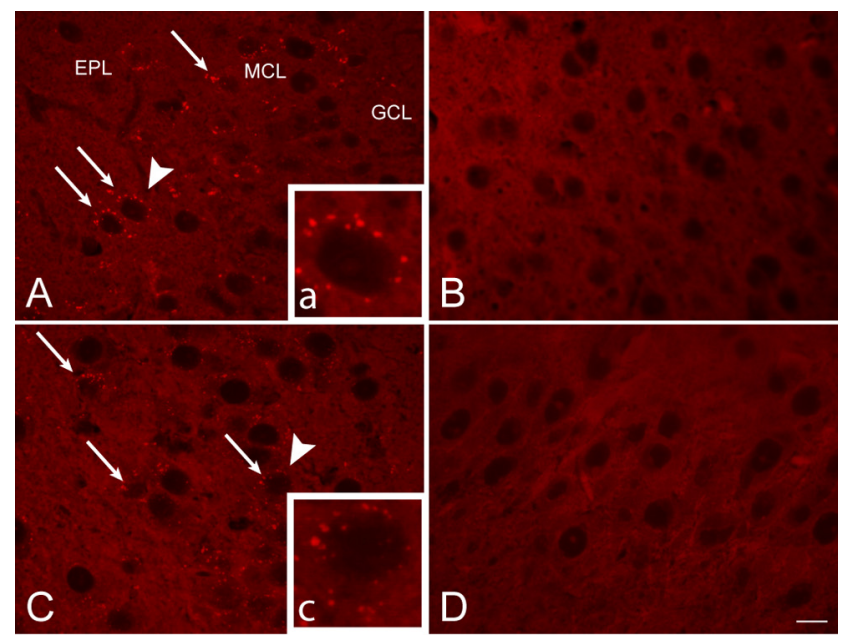

Figure 1. Ghrelin binding in rat brain areas involved in olfactory processing. Biotinylated ghrelin (red fluorescence) binding was found on or in scattered cell bodies in the MOB $(\boldsymbol{A})$ and hippocampus (C). Biotinylated ghrelin binding was abolished in the $\mathrm{MOB}(\boldsymbol{B})$ and hippocampus (D) when brain tissue was coincubated with unlabeled ghrelin. Arrows point to labeling, presumably at synaptic boutons, on cell bodies of neurons in the external plexiform (EPL), mitral cell (MCL), and granular cell (GCL) layers. Arrowheads point to areas being magnified ( $\boldsymbol{a}$ and $\boldsymbol{c}$ ). Scale bar: $A-D, 10 \mu \mathrm{m} ; \boldsymbol{a}, \boldsymbol{C}, 40 \mu \mathrm{m}$.
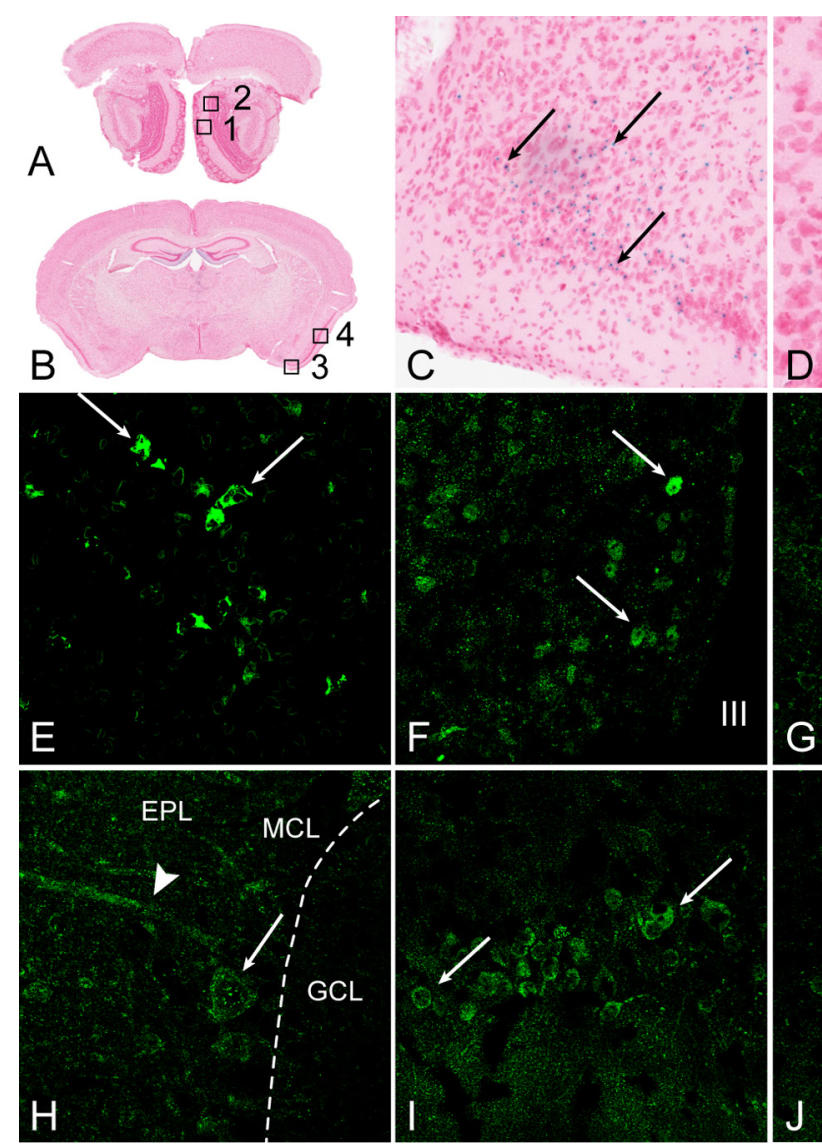

III

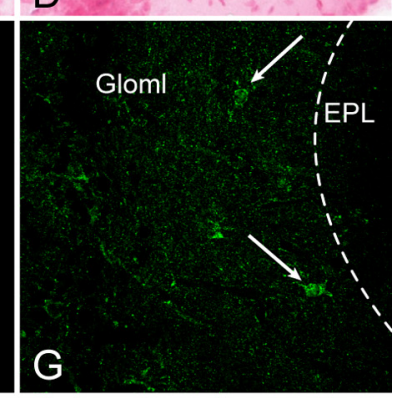

Figure 2. Ghrelin receptor (GHSR) localization in mouse brain areas involved in sniffing and olfactory behaviors. $A, B$, Cresyl violetstained coronal sections of $M O B(A)$ and brain $(B)$, with boxes indicating regions shown at higher magnification in $C, D$, and $G-J$. Box $1, M O B$ glomerular layer (Gloml) (shown in G); box 2, MOB, junction between external plexiform (EPL), mitral cell (MCL), and granular cell (GCL) layers $(\boldsymbol{H})$; box 3. anterior cortical amygdala $(\boldsymbol{C}, \boldsymbol{I})$; and box 4 , piriform cortex $(\boldsymbol{D}, \boldsymbol{J}) . \boldsymbol{C}-\boldsymbol{J}$, Immunofluorescent and histochemical staining of $X$-gal in tissues from ko mice. $\boldsymbol{E}-\boldsymbol{J}, \beta$-gal immunofluorescence wasseen in the pituitary $(\boldsymbol{E})$ and hypothalamus $(\boldsymbol{F})$; in cells in the MOB $G$ loml ( $\mathbf{G}$; cell bodies, arrow) and in MOB mitral cells ( $\boldsymbol{H}$; cell body, arrow; dendrite in EPL, arrowhead); and in neurons (arrows) in the cortical amygdala $(I)$ and piriform cortex $(J)$. III, Third ventricle. $C, D$, Scattered cells positive for $\beta$-gal histochemical staining were visible in the cortical amygdala ( $($ ) and piriform cortex (D). Scale bar: $\boldsymbol{D}-\mathbf{G}, \boldsymbol{I}, \boldsymbol{J}, 50 \mu \mathrm{m} ; \boldsymbol{H}, 33 \mu \mathrm{m} ; \boldsymbol{C}, 100 \mu \mathrm{m}$. 


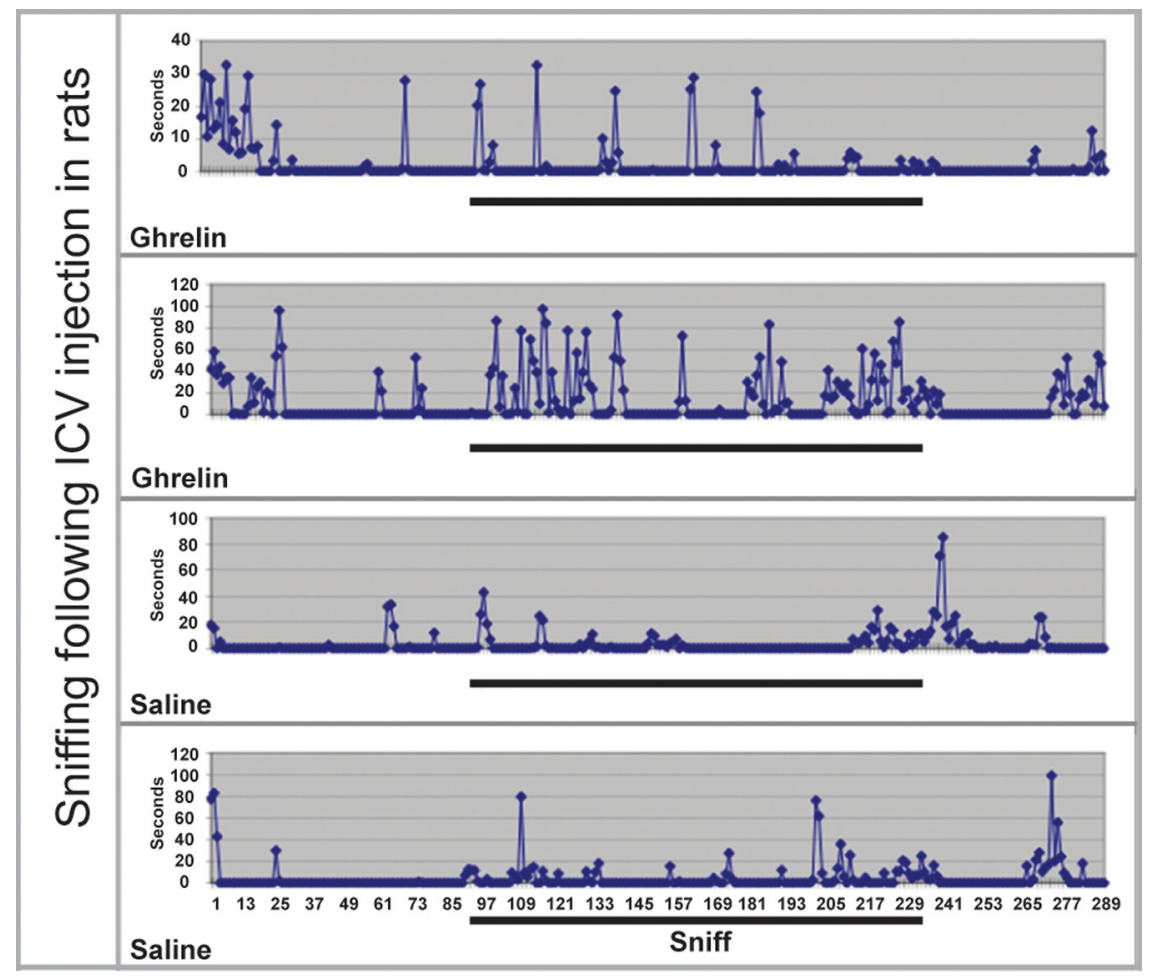

Figure 3. Sniff behavior was recorded for $24 \mathrm{~h}$ in rats after intracerebroventricular administration of ghrelin or vehicle control. Intracerebroventricular ghrelin (compared to intracerebroventricular vehicle) resulted in acutely increased sniffing frequency for up to $2 \mathrm{~h}$, and also increased sniffing throughout the dark phase.

havior and odorized water consumption using a two-tube device have been described previously (Aimé et al., 2007). Briefly, rats were first trained to drink pure water in the experimental cage for $3 \mathrm{~d}$. Then, for $2 \mathrm{~d}$, the water was odorized with isoamyl acetate (ISO, Sigma) at 1:100,000 $\left(10^{-5}\right)$, a dilution at which ISO can be detected only via olfaction in rats (Slotnick et al., 1997). During this training, ISO consumption above 0.5 $\mathrm{ml}$ was followed (15 min later) by an injection of malaise-inducing $\mathrm{LiCl}$ $(10 \mathrm{ml} / \mathrm{kg}, 0.15 \mathrm{M}$, i.p.). Rats failing to display a COA were given a second $\mathrm{LiCl}$ injection.

After this, during the behavioral testing period, rats were offered a choice between pure water and water odorized with ISO at $10^{-10}, 10^{-9}$, $10^{-8}$, or $10^{-7}$ on sequential days. The establishment of COA was confirmed at the end of the test period. Ghrelin $(2.5 \mathrm{nmol} / \mathrm{d}$, i.c.v. $)$ was delivered throughout the behavioral test via an osmotic minipump implanted $3 \mathrm{~d}$ prior. Lick responses were analyzed using SciPy and MySQL database software (Open Source Licenses). An olfactory detection index (ODI) was calculated as the proportion of the number of licks from the pure water tube relative to the total number of licks from both the odorized and pure water tubes. Higher ODI values indicated an increased ability to detect the ISO odor, less odorized water consumption, and enhanced odor detection. Average ODIs at each ISO concentration were compared between saline $(n=9)$ and ghrelin $(n=10)$ treatment groups.

Human sniffing behavior. Healthy, nonobese subjects $(n=9$, range $18-50$ years) were recruited from the greater Cincinnati area ( 7 males, 2 females; mean age $26 \pm 3.8$ years, mean body-mass index $24.1 \pm 1.2$ $\mathrm{kg} / \mathrm{m}^{2}$ ). Subjects with a history of asthma, seasonal allergies, or nasal steroid use were excluded. All subjects provided written informed consent as approved by the University of Cincinnati Institutional Review Board.

Sniffing behavior was evaluated using the sniff magnitude test (SMT) as described previously (Frank et al., 2003, 2006). Briefly, a canister was placed $\sim 2 \mathrm{~cm}$ beneath the nose, and subjects were instructed to take a single, natural sniff as would be taken when sampling a perfume or food. The stimuli used were as follows: nonodorized air, baby power odor (baby power fragrance oil, 50\% dilution, The Good Scents Co.), banana odor (isoamyl acetate, $1 \%$ dilution, Sigma-Aldrich), and tomato odor and rosemary chicken odor (both undiluted, formulated by Givaudan). Three sniffing trials were collected for each odorant and six for air. A specialized software program (Frank et al., 2006) identified the initiation of sniffing, recorded sniff pressure at $10 \mathrm{~ms}$ intervals, summed sniff pressures, and measured each sniff's duration during a $5 \mathrm{~s}$ sampling period. The sum of the pressure values was defined as the sniff magnitude. The subjects were also asked to rate the pleasantness of the odors immediately after each trial using a visual analog scale [scores ranging from -5 (slightly unpleasant) to 15 (best smell ever)]. The order of stimulus presentation was randomized. The average sniff magnitude and odor pleasantness ratings were used for data analysis.

The SMT was administered twice for each subject at each study visit, always after a $10 \mathrm{~h}$ fast. The first test was performed before any infusions, and the second was administered 45 min after the infusion of either $0.9 \%$ saline or synthetic human ghrelin (Bachem) at 1, 3, or 5 $\mu \mathrm{g} / \mathrm{kg} / \mathrm{h}$ (i.v.), on four separate occasions in a counterbalanced fashion (Tong et al., 2010). The infusion days were at least $3 \mathrm{~d}$ apart.

Statistical analysis. The ODI was compared between rat groups receiving ghrelin or saline (control), at each odor concentration, using a two-sample $t$ test. In the human study, changes in sniff magnitude and odor pleasantness rating, before and after saline or ghrelin infusions, were compared within subjects using a onefactor ANOVA. Average values are presented as mean \pm SEM unless specified otherwise. A $p$ value $<0.05$ was considered statistically significant. Data analysis was performed using GraphPad Prism version 5.0 (GraphPad Software).

\section{Results}

Ghrelin receptor localization in sniff and olfaction pathways Ghrelin binding and expression patterns of ghrelin receptors in olfactory bulbs and brain centers processing olfactory signals were assessed to determine whether ghrelin might directly modulate odor-induced activity in circuits of the central olfactory pathway. Clearly detectable binding of biotinylated ghrelin was seen in the olfactory bulb (Fig. 1A), suggesting that ghrelin is involved in olfactory processing. In addition to the arcuate, lateral hypothalamus, cortex, and paraventricular nucleus (PVN) as previously shown (Cowley et al., 2003), biotinylated ghrelin binding was also detected in the hippocampus (Fig. 1C), where GHSR is present (Zigman et al., 2006). This binding was specific, since it was prevented by pretreatment with an excess of unlabeled ghrelin (Fig. $1 B, D$ ). To confirm that ghrelin binding was due to expression of the only known receptor for ghrelin, GHSR, LacZ-reporter gene expression was evaluated in brain regions of Ghsr ko mice using X-gal immunofluorescent and histochemical staining. As expected, $\beta$-gal staining was present in pituitary (Fig. $2 E$ ) and hypothalamus (Fig. $2 F$ ), known areas of GHSR expression (Howard et al., 1996). Moderate to high levels of $\beta$-gal expression were also detected in the glomerular (Fig. 2G), mitral cell (Fig. $2 H$ ), and granular cell (supplemental Fig. $1 C$, available at www.jneurosci.org as supplemental material) layers of the main olfactory bulb (MOB), as well as in the accessory olfactory bulb (supplemental Fig. $1 A$, available at www.jneurosci.org as supplemental material). Staining was also noted in the anterior cortical amygdala (Fig. 2C,I), piriform cortex (Fig. $2 D, J$ ), and PVN (sup- 
plemental Fig. $1 B$, available at www.jneurosci.org as supplemental material). Overall, this evidence that ghrelin acts in these olfactory circuits supports the hypothesis that ghrelin modulates olfactory behavior.

\section{Ghrelin enhances sniffing in rats}

Acute intracerebroventricular ghrelin induced a rapid and robust increase in sniffing in rats compared to controls receiving vehicle infusions (Fig. 3). Sniffing bouts were highest immediately after acute ghrelin injection compared to controls, and during the ensuing dark phase, bouts of sniffing were again higher in ghrelintreated compared to control rats, indicating a sustained action of ghrelin on olfactory behavior. These data are consistent with the hypothesis that ghrelin acts in the brain to modulate sniffing behavior.

\section{Ghrelin increases odor detection in rats}

Avoidance of odorized water was close to $100 \%$ for both intracerebroventricular ghrelin-treated and vehicle-treated rats at the beginning and end of behavioral testing, confirming the COA paradigm. Fed rats treated with intracerebroventricular ghrelin consumed significantly less odorized water at the lowest concentration $\left(10^{-10}\right)$ than those treated with saline, as reflected by the higher ODI (85.1 \pm 6.5 vs $56.9 \pm 9.1$, respectively, $t=2.57, p=$ $0.02)$, while there were no differences at higher concentrations (data not shown). No differences in ODI were observed in fasted rats $(74.4 \pm 12.3$ vs $71.8 \pm 13.1, t=0.14, p=0.97)$, and there was no significant interaction between fasting/fed state and treatment $(p=0.23)$. These data suggest that central ghrelin administration reduces the olfactory detection threshold and improves olfactory sensitivity in fed rats.

\section{Ghrelin enhances exploratory sniffing in humans}

In humans, $45 \mathrm{~min}$ of ghrelin at doses of 1,3 , and $5 \mu \mathrm{g} / \mathrm{kg} / \mathrm{h}$ (i.v.) raised circulating plasma total ghrelin levels from $1049 \pm 270$ $\mathrm{pg} / \mathrm{ml}$ to $4659 \pm 168,15,738 \pm 3633$, and $23,954 \pm 5516 \mathrm{pg} / \mathrm{ml}$, respectively. The cumulative sniff magnitude increased significantly for all three doses as compared to saline $(p<0.001$ for all comparisons after Bonferroni correction) (Fig. 4A). When individual odorant trials were analyzed separately, both food- and non-food-related odorant and air trials all showed increased sniff magnitude in response to ghrelin infusion (Fig. $4 B-F$ ). Interestingly, the tomato odorant, but not the other single odorants, had a significant and selective increase of sniff magnitude with the 1 $\mu \mathrm{g} / \mathrm{kg} / \mathrm{h}$ ghrelin infusion compared to saline (adjusted $p=0.03$, one-way ANOVA).

Ratings obtained after each of the sniff trials indicated no difference in the odor pleasantness score before or after ghrelin infusion for any of the odorants tested ( $p>0.05$ for all comparisons) (supplemental Fig. 2, available at www.jneurosci.org as supplemental material). There was no association between odor rating change and sniff magnitude change (data not shown).

\section{Discussion}

We have found that ghrelin, a potent orexigenic peptide, influences olfactory function in rodents and humans by modulating sniffing behavior and olfactory detection thresholds. In addition to these physiologic actions, our work provides neuroanatomic support for ghrelin modulation of olfaction, since GHSR expression was observed in both main and accessory areas of the olfactory bulb, suggesting a means for ghrelin to directly modulate bulbar neuronal responses upon odorant stimulation. Collectively, our results support an extended influence of ghrelin on

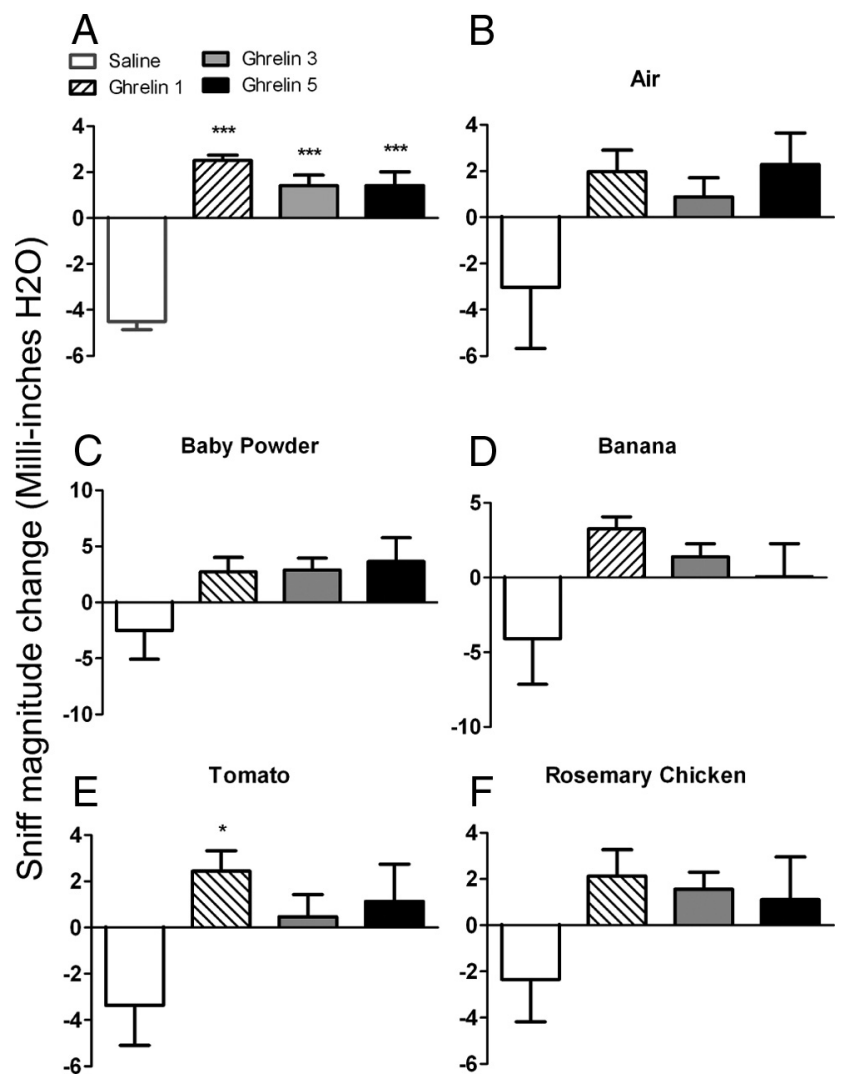

Figure 4. The SMT was administered before and $45 \mathrm{~min}$ after human subjects received ghrelin (1, 3, or $5 \mu \mathrm{g} / \mathrm{kg} / \mathrm{h}$ ) or saline intravenous infusions. Sniff magnitude changes are shown in the presence (hatched, gray, and black bars) or absence (white bar) of ghrelin administration, when the following odorants were presented to subjects in random order: air $(\boldsymbol{B})$, baby powder $(\boldsymbol{C})$, banana $(\boldsymbol{D})$, tomato $(\boldsymbol{E})$, and rosemary chicken $(\boldsymbol{F})$. The effect of ghrelin on sniff magnitude changes combining five odor trials is shown in $A .{ }^{*} p<0.05,{ }^{* * *} p<0.001$.

food intake that now includes modulating olfaction via different yet complementary physiological pathways.

In addition to increasing food intake per se, ghrelin enhances food-seeking behaviors such as foraging and food hoarding (Keen-Rhinehart and Bartness, 2005), and its plasma levels increase in anticipation of eating (Drazen et al., 2006). All of these are consistent with our finding that ghrelin controls sniff responses in rodents and humans, and previous findings that food odors detected orthonasally appear to be predictive cues anticipating nutrient availability (Small et al., 2005). Importantly, while nutritional states are known to modulate cortical neuronal responses to odorants (Critchley and Rolls, 1996; O'Doherty et al., 2000), the actual mechanism underlying the control of olfactory perception by nutritional status remains largely uncovered. Our finding of the presence of ghrelin receptors in olfactory circuits, as well as ghrelin-mediated modulation of odorant detection, raises a novel putative mechanism through which energy state might interact with olfactory chemosensory processing.

Previous studies identified links between olfaction and other appetite-modulating hormones. In rodents, the anorectic hormone leptin and the orexigenic hormone orexin alter foodseeking behavior and affect olfactory detection thresholds (Getchell et al., 2006; Julliard et al., 2007; Prud'homme et al., 2009). Our finding of enhanced olfactory sensitivity with concomitant increases in sniffing following central ghrelin administration suggests that one of the mechanisms through which metabolic hormones regulate olfaction may involve modulating 
sniffing. The importance of sniffing responses to olfactory function is well established, with high nostril flow rate associated with enhanced odorant detection (Laing, 1983; Sobel et al., 2000). In fact, even in the absence of detectable odorants, sniffing alone is able to generate an olfactory perception (Hughes et al., 1969; Sobel et al., 1998). Therefore, the enhanced olfactory function we observed was likely due to both increased sniffing and direct ghrelin action on neuronal circuits encoding olfactory perceptions.

Our study, combined with prior reports, provides clear evidence that ghrelin and its receptor, GHSR-1a, are present in central olfactory pathways (i.e., the olfactory bulb, piriform cortex, amygdala, brainstem, hippocampus, and the hypothalamus) (Figs. 1, 2) (Cowley et al., 2003; Zigman et al., 2006), as well as in brain regions involved in voluntary control of sniffing, including sensory motor cortex and brainstem (Guan et al., 1997; Katayama et al., 2000). It is important to note that majority of the effects observed in our study were obtained with central ghrelin administration, suggesting that circulating peptide may not be necessary.

Little is known about how hunger, or specifically elevated ghrelin levels, affects olfaction and voluntary sniffing in humans. Sniffing is influenced not only by the characteristics of an odor, but also by motivation factors as demonstrated in an experiment that individuals sniff harder toward water (no odor) than pleasant or unpleasant rated odors (Raudenbush et al., 1998). Intriguingly, our SMTs in humans revealed an increase in response to ghrelin administration that was not specific to odorant type (food- and non-food-related odors), nor even required odorant presence (air) (Fig. 4). This finding indicates that ghrelin was affecting exploratory sniffing rather than perceptual processing of the odors. Moreover, contrary to our expectations, ghrelin administration did not alter subjective odor pleasantness ratings in humans (supplemental material, available at www.jneurosci. org). Because hunger per se increases pleasantness ratings of food odors in humans (Duclaux et al., 1973; O'Doherty et al., 2000), our findings suggest that this does not depend on changes in ghrelin. In fact, only total but not acylated (active) ghrelin level has been associated with the pleasantness rating of 1 of the 6 essential oils (Trellakis et al., 2011). Rather, ghrelin may function to potentiate "olfactory arousal" by increasing sniff rates and odor detection ability. This function may extend to other sensory modalities, as suggested by the report that ghrelin increases CNS response to food pictures in humans (Malik et al., 2008). More broadly, our studies contribute to further clarifying the relationship between ghrelin levels and food reward.

In summary, we used a translational approach to demonstrate for the first time that ghrelin, a unique stomach-derived hormone that is known to stimulate eating and promote positive energy balance, potentiates the efficiency of food-seeking behaviors by enhancing exploratory sniffing and olfactory sensitivity in rodents and humans. Our findings indicate that the ghrelin system represents an important molecular interface between the environment and metabolic homeostasis, which senses nutrient availability and regulates essential mammalian behaviors such as food-seeking behavior.

\section{References}

Aimé P, Duchamp-Viret P, Chaput MA, Savigner A, Mahfouz M, Julliard AK (2007) Fasting increases and satiation decreases olfactory detection for a neutral odor in rats. Behav Brain Res 179:258-264.

Cowley MA, Smith RG, Diano S, Tschöp M, Pronchuk N, Grove KL, Strasburger CJ, Bidlingmaier M, Esterman M, Heiman ML, Garcia-Segura LM, Nillni EA, Mendez P, Low MJ, Sotonyi P, Friedman JM, Liu H, Pinto S,
Colmers WF, Cone RD, et al. (2003) The distribution and mechanism of action of ghrelin in the CNS demonstrates a novel hypothalamic circuit regulating energy homeostasis. Neuron 37:649-661.

Critchley HD, Rolls ET (1996) Hunger and satiety modify the responses of olfactory and visual neurons in the primate orbitofrontal cortex. J Neurophysiol 75:1673-1686.

Cummings DE (2006) Ghrelin and the short- and long-term regulation of appetite and body weight. Physiol Behav 89:71-84.

Cummings DE, Purnell JQ, Frayo RS, Schmidova K, Wisse BE, Weigle DS (2001) A preprandial rise in plasma ghrelin levels suggests a role in meal initiation in humans. Diabetes 50:1714-1719.

Drazen DL, Vahl TP, D’Alessio DA, Seeley RJ, Woods SC (2006) Effects of a fixed meal pattern on ghrelin secretion: evidence for a learned response independent of nutrient status. Endocrinology 147:23-30.

Druce MR, Wren AM, Park AJ, Milton JE, Patterson M, Frost G, Ghatei MA, Small C, Bloom SR (2005) Ghrelin increases food intake in obese as well as lean subjects. Int J Obes (Lond) 29:1130-1136.

Duclaux R, Feisthauer J, Cabanac M (1973) [Effects of a meal on the pleasantness of food and nonfood odors in man]. Physiol Behav 10:1029-1033.

Frank RA, Dulay MF, Gesteland RC (2003) Assessment of the sniff magnitude test as a clinical test of olfactory function. Physiol Behav 78:195-204.

Frank RA, Gesteland RC, Bailie J, Rybalsky K, Seiden A, Dulay MF (2006) Characterization of the sniff magnitude test. Arch Otolaryngol Head Neck Surg 132:532-536.

Getchell TV, Kwong K, Saunders CP, Stromberg AJ, Getchell ML (2006) Leptin regulates olfactory-mediated behavior in ob/ob mice. Physiol Behav $87: 848-856$.

Goetzl FR, Stone F (1947) Diurnal variations in acuity of olfaction and food intake. Gastroenterology 9:444-453.

Guan XM, Yu H, Palyha OC, McKee KK, Feighner SD, Sirinathsinghji DJ, Smith RG, Van der Ploeg LH, Howard AD (1997) Distribution of mRNA encoding the growth hormone secretagogue receptor in brain and peripheral tissues. Brain Res Mol Brain Res 48:23-29.

Havermans RC, Janssen T, Giesen JC, Roefs A, Jansen A (2009) Food liking, food wanting, and sensory-specific satiety. Appetite 52:222-225.

Howard AD, Feighner SD, Cully DF, Arena JP, Liberator PA, Rosenblum CI, Hamelin M, Hreniuk DL, Palyha OC, Anderson J, Paress PS, Diaz C, Chou M, Liu KK, McKee KK, Pong SS, Chaung LY, Elbrecht A, Dashkevicz M, Heavens R, et al. (1996) A receptor in pituitary and hypothalamus that functions in growth hormone release. Science 273:974-977.

Hughes JR, Hendrix DE, Wetzel N (1969) Electrophysiological studies of the olfactory bulb in man-a model for EEG investigation. Electroencephalogr Clin Neurophysiol 27:661.

Julliard AK, Chaput MA, Apelbaum A, Aimé P, Mahfouz M, Duchamp-Viret $P$ (2007) Changes in rat olfactory detection performance induced by orexin and leptin mimicking fasting and satiation. Behav Brain Res 183:123-129.

Kampe J, Wiedmer P, Pfluger PT, Castaneda TR, Burget L, Mondala H, Kerr J, Liaw C, Oldfield BJ, Tschöp MH, Bagnol D (2006) Effect of central administration of QRFP(26) peptide on energy balance and characterization of a second QRFP receptor in rat. Brain Res 1119:133-149.

Katayama M, Nogami H, Nishiyama J, Kawase T, Kawamura K (2000) Developmentally and regionally regulated expression of growth hormone secretagogue receptor mRNA in rat brain and pituitary gland. Neuroendocrinology 72:333-340.

Keen-Rhinehart E, Bartness TJ (2005) Peripheral ghrelin injections stimulate food intake, foraging, and food hoarding in Siberian hamsters. Am J Physiol Regul Integr Comp Physiol 288:R716-R722.

Kepecs A, Uchida N, Mainen ZF (2007) Rapid and precise control of sniffing during olfactory discrimination in rats. J Neurophysiol 98:205-213.

Kojima M, Hosoda H, Date Y, Nakazato M, Matsuo H, Kangawa K (1999) Ghrelin is a growth-hormone-releasing acylated peptide from stomach. Nature 402:656-660.

Laing DG (1983) Natural sniffing gives optimum odour perception for humans. Perception 12:99-117.

LeSauter J, Hoque N, Weintraub M, Pfaff DW, Silver R (2009) Stomach ghrelin-secreting cells as food-entrainable circadian clocks. Proc Natl Acad Sci U S A 106:13582-13587.

Mainland J, Sobel N (2006) The sniff is part of the olfactory percept. Chem Senses 31:181-196.

Malik S, McGlone F, Bedrossian D, Dagher A (2008) Ghrelin modulates 
brain activity in areas that control appetitive behavior. Cell Metab 7:400-409.

Mozell MM, Jagodowicz M (1973) Chromatographic separation of odorants by the nose: retention times measured across in vivo olfactory mucosa. Science 181:1247-1249.

Nogueiras R, Wiedmer P, Perez-Tilve D, Veyrat-Durebex C, Keogh JM, Sutton GM, Pfluger PT, Castaneda TR, Neschen S, Hofmann SM, Howles PN, Morgan DA, Benoit SC, Szanto I, Schrott B, Schürmann A, Joost HG, Hammond C, Hui DY, Woods SC, et al. (2007) The central melanocortin system directly controls peripheral lipid metabolism. J Clin Invest 117:3475-3488.

O’Doherty J, Rolls ET, Francis S, Bowtell R, McGlone F, Kobal G, Renner B, Ahne G (2000) Sensory-specific satiety-related olfactory activation of the human orbitofrontal cortex. Neuroreport 11:893-897.

Prud'homme MJ, Lacroix MC, Badonnel K, Gougis S, Baly C, Salesse R, Caillol M (2009) Nutritional status modulates behavioural and olfactory bulb Fos responses to isoamyl acetate or food odour in rats: roles of orexins and leptin. Neuroscience 162:1287-1298.

Raudenbush B, Schroth F, Reilley S, Frank RA (1998) Food neophobia, odor evaluation and exploratory sniffing behavior. Appetite 31:171-183.

Slotnick BM, Westbrook F, Darling FMC (1997) What the rat's nose tells the rat's mouth: long delay aversion conditioning with aqueous odors and potentiation of taste by odors. Anim Learn Behav 25:357-369.

Small DM, Gerber JC, Mak YE, Hummel T (2005) Differential neural responses evoked by orthonasal versus retronasal odorant perception in humans. Neuron 47:593-605.

Sobel N, Prabhakaran V, Desmond JE, Glover GH, Goode RL, Sullivan EV, Gabrieli JD (1998) Sniffing and smelling: separate subsystems in the human olfactory cortex. Nature 392:282-286.

Sobel N, Khan RM, Hartley CA, Sullivan EV, Gabrieli JD (2000) Sniffing longer rather than stronger to maintain olfactory detection threshold. Chem Senses 25:1-8.
Steele AD, Jackson WS, King OD, Lindquist S (2007) The power of automated high-resolution behavior analysis revealed by its application to mouse models of Huntington's and prion diseases. Proc Natl Acad Sci U S A 104:1983-1988.

Theander-Carrillo C, Wiedmer P, Cettour-Rose P, Nogueiras R, Perez-Tilve D, Pfluger P, Castaneda TR, Muzzin P, Schürmann A, Szanto I, Tschöp MH, Rohner-Jeanrenaud F (2006) Ghrelin action in the brain controls adipocyte metabolism. J Clin Invest 116:1983-1993.

Tong J, Prigeon RL, Davis HW, Bidlingmaier M, Kahn SE, Cummings DE, Tschöp MH, D’Alessio D (2010) Ghrelin suppresses glucose-stimulated insulin secretion and deteriorates glucose tolerance in healthy humans. Diabetes 59:2145-2151

Trellakis S, Tagay S, Fischer C, Rydleuskaya A, Scherag A, Bruderek K, Schlegl S, Greve J, Canbay AE, Lang S, Brandau S (2011) Ghrelin, leptin and adiponectin as possible predictors of the hedonic value of odors. Regul Pept 167:112-117.

Tschöp M, Smiley DL, Heiman ML (2000) Ghrelin induces adiposity in rodents. Nature 407:908-913.

Tschöp M, Wawarta R, Riepl RL, Friedrich S, Bidlingmaier M, Landgraf R, Folwaczny C (2001) Post-prandial decrease of circulating human ghrelin levels. J Endocrinol Invest 24:RC19-21.

Wortley KE, Anderson KD, Garcia K, Murray JD, Malinova L, Liu R, Moncrieffe M, Thabet K, Cox HJ, Yancopoulos GD, Wiegand SJ, Sleeman MW (2004) Genetic deletion of ghrelin does not decrease food intake but influences metabolic fuel preference. Proc Natl Acad Sci U S A 101:8227-8232.

Yi CX, van der Vliet J, Dai J, Yin G, Ru L, Buijs RM (2006) Ventromedial arcuate nucleus communicates peripheral metabolic information to the suprachiasmatic nucleus. Endocrinology 147:283-294.

Zigman JM, Jones JE, Lee CE, Saper CB, Elmquist JK (2006) Expression of ghrelin receptor mRNA in the rat and the mouse brain. J Comp Neurol 494:528-548. 